\section{(O) OPEN ACCESS}

\title{
Association between environmental tobacco smoke exposure and dementia syndromes
}

\author{
Ruoling Chen, ${ }^{1,6}$ Kenneth Wilson, ${ }^{2}$ Yang Chen, ${ }^{3}$ Dongmei Zhang, ${ }^{1,4}$ Xia Qin, ${ }^{1}$ \\ Meizi He, ${ }^{5}$ Zhi Hu, ${ }^{1}$ Ying Ma, ${ }^{1}$ John $\mathrm{R}$ Copeland ${ }^{2}$
}

\begin{abstract}
${ }^{1}$ School of Health
Administration, Anhui Medical

University, Hefei, China

${ }^{2}$ Division of Psychiatry,

University of Liverpool,

Liverpool, UK

${ }^{3}$ Green Templeton College, University of Oxford, Oxford, UK

${ }^{4}$ School of Health and Wellbeing, University of Wolverhampton, Wolverhampton, UK ${ }^{5}$ Department of Health and Kinesiology, University of Texas at San Antonio, San Antonio, Texas, USA

${ }^{6}$ Division of Health and Social Care Research, King's College London, London, UK
\end{abstract}

\section{Correspondence to}

Dr Ruoling Chen, Department of Primary Care and Public Health, Division of Health and Social Care Research, King's College London, 7th Floor, Capital House, 42 Weston Street, London SE1 3QD, UK; ruoling.chen@kcl.ac.uk

Received 16 March 2012 Revised 20 August 2012 Accepted 17 September 2012 Published Online First 26 October 2012

\footnotetext{
To cite: Chen $\mathrm{R}$, Wilson $\mathrm{K}$, Chen $Y$, et al. Occup Environ Med 2013, 70, 63-69.
}

\begin{abstract}
Objectives Environmental tobacco smoke (ETS) has a range of adverse health effects, but its association with dementia remains unclear and with dementia syndromes unknown. We examined the dose-response relationship between ETS exposure and dementia syndromes. Methods Using a standard method of GMS, we interviewed 5921 people aged $\geq 60$ years in five provinces in China in 2007-2009 and characterised their ETS exposure. Five levels of dementia syndrome were diagnosed using the Automated Geriatric Examination for Computer Assisted Taxonomy instrument. The relative risk (RR) of moderate (levels 1-2) and severe (levels 3-5) dementia syndromes among participants exposed to ETS was calculated in multivariate adjusted regression models.
\end{abstract}

Results 626 participants (10.6\%) had severe dementia syndromes and 869 (14.7\%) moderate syndromes. Participants exposed to ETS had a significantly increased risk of severe syndromes (adjusted RR 1.29, 95\% Cl 1.05 to 1.59 ). This was dose-dependently related to exposure level and duration. The cumulative exposure dose data showed an adjusted RR of $0.99(95 \% \mathrm{Cl} 0.76$ to 1.28$)$ for $>0-24$ level years of exposure, $1.15(95 \%$ $\mathrm{Cl} 0.93$ to 1.42$)$ for $25-49$ level years, $1.18(95 \% \mathrm{Cl}$ 0.87 to 1.59$)$ for $59-74$ level years, $1.39(95 \% \mathrm{Cl} 1.03$ to 1.84$)$ for $75-99$ level years and $1.95(95 \% \mathrm{Cl} 1.34$ to 2.83 ) for $\geq 100$ level years. Significant associations with severe syndromes were found in never smokers and in former/current smokers. There were no positive associations between ETS and moderate dementia syndromes.

Conclusions ETS should be considered an important risk factor for severe dementia syndromes. Avoidance of ETS may reduce the rates of severe dementia syndromes worldwide.

\section{BACKGROUND}

Dementia syndromes are comprehensive chronic mental disorders, the main clinical features being cognitive decline and varying degrees of personality change. They comprise Alzheimer's disease, vascular dementia and other rarer conditions. Dementia syndromes are relatively common, increasing in prevalence, and the largest cause of disability, particularly disability that affects self-care and the ability to carry out domestic tasks. ${ }^{1}$ They are one of the world's biggest health problems and a major public health challenge that is increasing as populations age. ${ }^{2}$

\section{What this paper adds}

- Environmental tobacco smoke (ETS) increases the risks of cancer, and respiratory and cardiovascular diseases, but its association with dementia remains unclear.

- No study has previously investigated the doseresponse relationship between ETS and dementia syndromes.

- The risk of severe dementia syndromes was dose-dependently increased with ETS exposure.

- The effect was similar between never smokers and smokers, and was predominately due to ETS exposure at work.

- ETS should be considered an important risk factor for severe dementia syndromes.

Previous studies have shown that cigarette smoking substantially increases the risk of Alzheimer's disease and all types of dementia. ${ }^{3} 4$ This has stimulated speculation that environmental tobacco smoke (ETS), also known as second-hand smoke or passive smoking, may also have a role. In a recent study, Llewellyn $e t a l^{5}$ reported a significant association between ETS and cognitive impairment (defined by the lowest $10 \%$ of scores on a battery of neuropsychological tests) in a UK population aged $\geq 50$. In Italy, Orsitto et $a l^{6}$ observed that both mild cognitive impairment and dementia were related to ETS in 856 patients aged $\geq 65$ who were consecutively admitted to a geriatric unit. In the USA, however, Barnes $\mathrm{et}_{\mathrm{al}} \mathrm{l}^{7}$ did not find a significant relationship between ETS and risk of dementia in a cohort of 970 older people. The uncertain association between ETS exposure and risk of dementia is compounded by lack of data, urging further investigation. In this study, we examine the dose-response relationship between ETS exposure and dementia syndromes (as opposed to dementia cases).

\section{METHODS}

Study populations were derived from a fourprovince study of dementia, ${ }^{8}$ and also from the third wave survey of the Anhui study, ${ }^{9}$ to increase the study power.

\section{The four-province study}

The methods employed in the four-province study have been fully described before. ${ }^{8}$ In brief, in 
2008-2009, following our previous studies in Anhui province, ${ }^{10} 11$ we chose one urban and one rural community from each of four provinces (Guangdong, Heilongjiang, Shanghai and Shanxi) as the study fields and sought to recruit 500 or more participants from each community. We employed a cluster random sampling method to select residential communities from each of the four provinces (detailed location data are available on request). The target population consisted of residents aged $\leq 60$ years who had lived in the area for at least 5 years. Ethics approval for the study was obtained from the Research Ethics Committee, University College London, UK, and the local governments in China. Based on the residency lists of the district and village committees, we recruited a total of 4314 participants, with an overall response rate of $93.8 \%$. Permission for interview and informed consent were obtained from each participant or, if that was not possible, from the closest responsible adult. The participants were interviewed at home by each local survey team from Guangzhou, Harbing and Shanxi Medical Universities, and the School of Public Health of Fudan University. Two researchers from each team were trained at Anhui Medical University, where we had completed several surveys of mental illness in older people and had a skilled and experienced interview team. ${ }^{9-11}$ Researchers then returned to their own centres, passed on their skills to local research teams and re-trained the interviewers. The main interview materials were a general health and risk factors questionnaire ${ }^{9}$ and the Geriatric Mental State Examination (GMS)—a comprehensive semi-structured mental state interview. ${ }^{8} 12$ According to standard procedures, ${ }^{13} 14$ we measured systolic and diastolic blood pressure, and weight and waist circumference in all participants.

\section{The third wave survey of the Anhui study}

The methods employed in the different wave surveys of the Anhui study have been described previously. ${ }^{9}$ In brief, in 2001-2003 we examined a random sample of 3336 men and women aged $\leq 60$ years in urban and rural Anhui, China (wave 1) using the standard GMS method. ${ }^{12}$ After completing the wave 2 interview in the year following the baseline investigation, ${ }^{15}$ we carried out the third wave survey during 2007-2009 and successfully re-interviewed 1757 participants, obtaining a response rate of $82.4 \%$ of surviving cohort members. ${ }^{9}$ The third wave interview protocol was similar to that in the fourprovince study mentioned above, and was described in a previous publication. ${ }^{9}$

\section{Assessment of dementia syndromes}

A computer program-assisted diagnosis system, the Automated Geriatric Examination for Computer Assisted Taxonomy (AGECAT), ${ }^{12}$ was used to analyse the information from the GMS to identify the principal mental disorders in the study participants. AGECAT was developed using a theoretical model and tested on sample populations diagnosed by psychiatrists. It first attempts to replicate the process by which a psychiatrist diagnoses a syndrome, and then offers a differential diagnosis. GMS symptoms are combined into 150 'symptom components'. In stage I, the symptom components are assembled into groups that characterise the major symptoms of each syndrome. The scores on these individual groups determine the confidence of the diagnosis of the syndrome level. Thus the system uses both quantitative and qualitative measures to determine levels of confidence and utilises numerous clinical decisions to allocate symptom components to syndrome levels. Levels of confidence of diagnosis (0-5) for individual participants are assigned for each of the eight diagnostic syndromes: organic disorder, depression, mania, schizophrenia and paranoia, obsession, phobia, hypochondria, and general anxiety. ${ }^{16}$ In stage II the various syndrome levels are compared with each other to derive a final differential diagnosis and a level of confidence of diagnosis (0-5). A level of $\geq 3$ in most circumstances designates a 'case level', which corresponds with what psychiatrists usually recognise as 'a case for intervention' for organic mental disorder. The GMS-AGECAT diagnosis has been validated in a variety of populations, ${ }^{12}$ including older Chinese populations. ${ }^{12} 17$

\section{Definition of ETS exposure}

We asked the participants for information on smoking habits and ETS exposures, using a questionnaire similar to that employed in the Scottish MONICA surveys. ${ }^{18} 19$ Current smokers were those who gave a positive answer to the question 'Do you smoke cigarettes now?' and provided additional information including the number of cigarettes smoked each day, the maximum number smoked each day in the last 2 years, and the duration of the smoking habit. If not currently smoking, participants were asked about their smoking history and related information. We defined 'never smokers' as those who gave negative answers to both enquiries. After giving details of smoking status, all participants were required to provide the answers 'yes' or 'no' relating to exposure to ETS. Three sources of ETS exposure were given; home, workplace, and other places, and respondents were given three choices: no, none at all; yes, some; or yes, a lot. All participants were asked how many years they were exposed to each of three sources of ETS.

\section{Statistical analysis}

The four-province data were combined with the Anhui wave 3 data for analysis (waves 1 and 2 did not have ETS data available). Of 6071 participants, 5962 reported smoking status, of whom 5928 had data on ETS exposure available. Exclusion of seven participants who did not have GMS-AGECAT data, left 5921 for analysis in this study. We defined levels 1-2 organic disorder syndromes as moderate dementia syndromes and levels 3-5 as severe syndromes. ${ }^{16}{ }^{20}$ We employed a Cox regression model used previously ${ }^{21} 22$ to calculate the RR of increased dementia syndromes among participants with ETS compared to those without. Moderate and severe syndromes were compared individually to each of the other syndromes. In the analysis we adjusted for age, sex, smoking status, urban/rural location, educational level, occupational class, annual income, marital status, religion, current drinking, visiting children or relatives, hypertension, stroke and depressive syndromes, and accounted for the clustering effect of the five-province geographical area in the model. We further investigated the RR for different sources of ETS exposure (at home, at work and in other locations) and their durations in relation to the excess of dementia syndromes. We scored the three exposure levels ('No, none at all', 'Yes, some' and 'Yes, a lot') as 0, 1 and 2, respectively, and calculated cumulative exposures by multiplying each score by exposure duration. We included cumulative exposure in the analysis. All analyses were performed in Stata V.11 (StataCorp, College Station, Texas, USA).

\section{RESULTS}

Of 5921 participants, 2153 (36.4\%) were exposed to ETS (1159 (30.8\%) of 3769 never smokers, and $994(46.2 \%)$ of 2152 former/current smokers) (table 1). In comparison to those without ETS exposure, ETS-exposed participants were significantly younger, and more likely to have smoked, live in a rural area, have lower education and occupational class, be married 
Table 1 Basic characteristics and dementia syndromes of participants with and without environmental tobacco smoke (ETS) exposure in the five-province study, China

\begin{tabular}{|c|c|c|c|c|c|}
\hline \multirow[b]{3}{*}{ Variable } & \multicolumn{5}{|c|}{ ETS exposure } \\
\hline & \multicolumn{2}{|c|}{ No $(n=3768)$} & \multicolumn{2}{|c|}{ Yes $(n=2153)$} & \multirow{2}{*}{$\begin{array}{l}p \\
\text { Value }\end{array}$} \\
\hline & $\mathrm{n}$ & $\%$ & $\mathbf{n}$ & $\%$ & \\
\hline \multicolumn{6}{|l|}{ Age } \\
\hline Mean (SD) & 72.99 & 7.53 & 72.02 & 7.43 & $<0.001$ \\
\hline \multicolumn{6}{|l|}{ Sex } \\
\hline Men & 1640 & 43.5 & 953 & 44.3 & 0.581 \\
\hline Women & 2128 & 56.5 & 1200 & 55.7 & \\
\hline \multicolumn{6}{|l|}{ Body mass index $\left(\mathrm{kg} / \mathrm{m}^{2}\right)$} \\
\hline$<25$ & 2692 & 74.9 & 1546 & 74.9 & 0.971 \\
\hline $25-29.9$ & 765 & 21.3 & 436 & 21.1 & \\
\hline$\geq 30$ & 137 & 3.8 & 81 & 3.9 & \\
\hline \multicolumn{6}{|l|}{ Smoking status } \\
\hline Never & 2610 & 69.3 & 1159 & 53.8 & $<0.001$ \\
\hline Former & 367 & 9.7 & 361 & 16.8 & \\
\hline Current & 791 & 21.0 & 633 & 29.4 & \\
\hline \multicolumn{6}{|l|}{ Urban/rural } \\
\hline Urban & 1986 & 52.7 & 783 & 36.4 & $<0.001$ \\
\hline Rural & 1782 & 47.3 & 1370 & 63.6 & \\
\hline \multicolumn{6}{|l|}{ Educational level } \\
\hline College/university & 234 & 6.2 & 88 & 4.1 & $<0.001$ \\
\hline High secondary school & 409 & 10.9 & 141 & 6.6 & \\
\hline Secondary school & 579 & 15.4 & 259 & 12.0 & \\
\hline Primary school & 900 & 23.9 & 598 & 27.8 & \\
\hline Illiterate & 1643 & 43.6 & 1064 & 49.5 & \\
\hline \multicolumn{6}{|l|}{ Main occupation } \\
\hline Official/teacher & 683 & 18.1 & 243 & 11.3 & $<0.001$ \\
\hline Manual labourer & 694 & 18.4 & 340 & 15.8 & \\
\hline Business & 23 & 0.6 & 16 & 0.7 & \\
\hline Housewife & 327 & 8.7 & 153 & 7.1 & \\
\hline Other & 291 & 7.7 & 122 & 5.7 & \\
\hline Farmer & 1748 & 46.4 & 1278 & 59.4 & \\
\hline \multicolumn{6}{|l|}{ Annual income } \\
\hline Very satisfactory & 343 & 9.1 & 179 & 8.3 & 0.519 \\
\hline Satisfactory & 1617 & 43.0 & 943 & 43.9 & \\
\hline Average & 1518 & 40.4 & 849 & 39.6 & \\
\hline Poor & 281 & 7.5 & 175 & 8.2 & \\
\hline \multicolumn{6}{|l|}{ Marriage } \\
\hline Married & 2519 & 66.9 & 1622 & 75.4 & $<0.001$ \\
\hline Widow & 1126 & 29.9 & 476 & 22.1 & \\
\hline Divorced & 19 & 0.5 & 10 & 0.5 & \\
\hline Never married & 101 & 2.7 & 44 & 2.0 & \\
\hline \multicolumn{6}{|l|}{ Having a religious belief } \\
\hline No & 3227 & 85.8 & 1740 & 81.0 & $<0.001$ \\
\hline Yes with religious activity & 368 & 9.8 & 282 & 13.1 & \\
\hline $\begin{array}{l}\text { Yes without religious } \\
\text { activity }\end{array}$ & 168 & 4.5 & 125 & 5.8 & \\
\hline \multicolumn{6}{|l|}{ Current drinking } \\
\hline No & 3258 & 86.6 & 1745 & 81.0 & $<0.001$ \\
\hline Yes & 505 & 13.4 & 408 & 19.0 & \\
\hline \multicolumn{6}{|l|}{ Visiting children or relatives } \\
\hline Every day & 1564 & 41.6 & 945 & 44.0 & $<0.001$ \\
\hline 1-3/week & 1287 & 34.2 & 611 & 28.4 & \\
\hline$\leq 1 /$ month & 908 & 24.2 & 592 & 27.6 & \\
\hline \multicolumn{6}{|l|}{ Hypertension } \\
\hline No & 1586 & 43.2 & 866 & 41.1 & 0.114 \\
\hline Yes & 2082 & 56.8 & 1241 & 58.9 & \\
\hline
\end{tabular}

Table 1 Continued

\begin{tabular}{|c|c|c|c|c|c|}
\hline \multirow[b]{3}{*}{ Variable } & \multicolumn{5}{|c|}{ ETS exposure } \\
\hline & \multicolumn{2}{|c|}{ No $(n=3768)$} & \multicolumn{2}{|c|}{ Yes $(n=2153)$} & \multirow{2}{*}{$\begin{array}{l}p \\
\text { Value }\end{array}$} \\
\hline & $\mathbf{n}$ & $\%$ & $\mathbf{n}$ & $\%$ & \\
\hline \multicolumn{6}{|l|}{ Diabetes } \\
\hline No & 3514 & 93.4 & 2015 & 93.8 & 0.499 \\
\hline Yes & 250 & 6.6 & 133 & 6.2 & \\
\hline \multicolumn{6}{|l|}{ Stroke } \\
\hline No & 3621 & 96.2 & 2065 & 96.3 & 0.893 \\
\hline Yes & 143 & 3.8 & 80 & 3.7 & \\
\hline \multicolumn{6}{|c|}{ Depressive syndrome (level) } \\
\hline 0 & 3351 & 88.9 & 1883 & 87.5 & 0.214 \\
\hline $1-2$ & 214 & 5.7 & 143 & 6.6 & \\
\hline $3-5$ & 203 & 5.4 & 127 & 5.9 & \\
\hline \multicolumn{6}{|c|}{ Dementia syndrome (level) } \\
\hline No & 2903 & 77.0 & 1523 & 70.7 & $<0.001$ \\
\hline $1-2$ & 531 & 14.1 & 338 & 15.7 & \\
\hline $3-5$ & 334 & 8.9 & 292 & 13.6 & \\
\hline
\end{tabular}

(versus widowed), have a religious belief, drink alcohol and visit children (table 1). There were no significant differences between exposed and non-exposed groups regarding body mass index, annual income, hypertension, diabetes, stroke and depressive syndrome. However, participants exposed to ETS had a significantly increased risk of dementia syndromes (table 1).

The age-sex adjusted analysis accounting for the clustering effect of the five-province geographical data showed a significantly increased relative risk for severe dementia syndromes $(1.61,95 \%$ CI 1.30 to $1.98 ; \mathrm{p}<0.001)$ but not for moderate syndromes $(1.14,95 \%$ CI 0.89 to $1.45 ; \mathrm{p}=0.305)$. After further adjustment for smoking status, urban/rural location, educational level, occupation, income, marital status, religion, current drinking, visiting children or relatives, hypertension, stroke and depressive syndrome, the RR was 1.29 (95\% CI 1.05 to 1.59 ; $\mathrm{p}=0.014)$ and $0.96(95 \%$ CI 0.84 to $1.09 ; \mathrm{p}=0.502)$, respectively. The corresponding figures for the four-province study were 1.33 (95\% CI 0.98 to 1.81 ) and 1.08 (95\% CI 0.94 to 1.24), and for the Anhui third wave survey 1.29 (95\% CI 0.99 to 1.68$)$ and 0.97 (95\% CI 0.78 to 1.22$)$.

Separate data analysis for never smokers and former/current smokers showed similar results: an increased risk of severe syndromes of 1.33 (95\% CI 1.01 to 1.74 ) in never smokers and 1.23 (95\% CI 1.02 to 1.49$)$ in former/current smokers, with corresponding figures for moderate syndromes of 1.06 (95\% CI 0.78 to 1.45 ) and 0.81 (95\% CI 0.57 to 1.17$)$, respectively.

Table 2 shows the numbers and percentages of participants with dementia syndromes in relation to different sources of ETS, exposure duration and cumulative exposure. The dementia syndromes were significantly related to ETS exposure across different sources, exposure duration and cumulative exposure. It appears that the more severe the syndrome, the stronger the association with ETS.

Table 3 shows the RR of severe syndromes in relation to different sources of ETS and cumulative exposures. The increased RR for all participants was consistent across different sources of exposure. The risk was significantly increased with duration of exposure at home, at work and in other locations, and with cumulative dose. A pattern of slightly increased RRs was seen in never smokers (table 3). Significant associations were also found 
Table 2 Dementia syndromes in participants with and without environmental tobacco smoke (ETS) exposure by exposure sources and duration in the five-province study, China

\begin{tabular}{|c|c|c|c|c|c|c|c|}
\hline \multirow[b]{3}{*}{ Source of ETS exposure } & \multicolumn{6}{|c|}{ Dementia syndrome level } & \multirow[b]{3}{*}{ p Value } \\
\hline & \multicolumn{2}{|l|}{$0(n=4426)$} & \multicolumn{2}{|l|}{$1-2(n=869)$} & \multicolumn{2}{|l|}{$3-5(n=626)$} & \\
\hline & $\mathrm{n}$ & $\%$ & $\mathrm{n}$ & $\%$ & $\mathrm{n}$ & $\%$ & \\
\hline \multicolumn{8}{|l|}{ Exposure level } \\
\hline \multicolumn{8}{|l|}{ At home } \\
\hline None & 2903 & 65.6 & 531 & 61.1 & 334 & 53.4 & $<0.001$ \\
\hline No & 432 & 9.8 & 54 & 6.2 & 33 & 5.3 & \\
\hline Yes* & 1091 & 24.6 & 284 & 32.7 & 259 & 41.4 & \\
\hline \multicolumn{8}{|l|}{ At work } \\
\hline None & 2903 & 65.6 & 531 & 61.1 & 334 & 53.4 & $<0.001$ \\
\hline No & 840 & 19.0 & 220 & 25.3 & 175 & 28.0 & \\
\hline Yes* & 683 & 15.4 & 118 & 13.6 & 117 & 18.7 & \\
\hline \multicolumn{8}{|l|}{ In other locations } \\
\hline None & 2903 & 65.6 & 531 & 61.1 & 334 & 53.4 & $<0.001$ \\
\hline No & 735 & 16.6 & 191 & 22.0 & 137 & 21.9 & \\
\hline Yes $^{*}$ & 788 & 17.8 & 147 & 16.9 & 155 & 24.8 & \\
\hline \multicolumn{8}{|l|}{ Above 3 combined } \\
\hline None & 2903 & 65.6 & 531 & 61.1 & 334 & 53.4 & $<0.001$ \\
\hline Some $(1-2) \dagger$ & 1212 & 27.4 & 287 & 33.0 & 230 & 36.7 & \\
\hline A lot $(3-6) \dagger$ & 311 & 7.0 & 51 & 5.9 & 62 & 9.9 & \\
\hline \multicolumn{8}{|l|}{ Exposure duration (years) } \\
\hline \multicolumn{8}{|l|}{ At home } \\
\hline None & 2903 & 65.6 & 531 & 61.1 & 334 & 53.4 & $<0.001$ \\
\hline No & 432 & 9.8 & 54 & 6.2 & 33 & 5.3 & \\
\hline$>0-19$ & 246 & 5.6 & 64 & 7.4 & 37 & 5.9 & \\
\hline $20-39$ & 535 & 12.1 & 112 & 12.9 & 101 & 16.1 & \\
\hline$\geq 40$ & 310 & 7.0 & 108 & 12.4 & 121 & 19.3 & \\
\hline \multicolumn{8}{|l|}{ At work } \\
\hline None & 2903 & 65.6 & 531 & 61.1 & 334 & 53.4 & $<0.001$ \\
\hline No & 840 & 19.0 & 220 & 25.3 & 175 & 28.0 & \\
\hline$>0-19$ & 118 & 2.7 & 28 & 3.2 & 22 & 3.5 & \\
\hline $20-39$ & 382 & 8.6 & 51 & 5.9 & 49 & 7.8 & \\
\hline$\geq 40$ & 183 & 4.1 & 39 & 4.5 & 46 & 7.3 & \\
\hline \multicolumn{8}{|l|}{ In other locations } \\
\hline None & 2903 & 65.6 & 531 & 61.1 & 334 & 53.4 & $<0.001$ \\
\hline No & 735 & 16.6 & 191 & 22.0 & 137 & 21.9 & \\
\hline$>0-19$ & 274 & 6.2 & 40 & 4.6 & 35 & 5.6 & \\
\hline 20-39 & 373 & 8.4 & 62 & 7.1 & 66 & 10.5 & \\
\hline$\geq 40$ & 141 & 3.2 & 45 & 5.2 & 54 & 8.6 & \\
\hline \multicolumn{8}{|l|}{ Above 3 combined score $\ddagger$} \\
\hline None & 2903 & 65.6 & 531 & 61.1 & 334 & 53.4 & $<0.001$ \\
\hline 1 & 196 & 4.4 & 48 & 5.5 & 32 & 5.1 & \\
\hline 2 & 480 & 10.8 & 96 & 11.0 & 56 & 8.9 & \\
\hline $3-4$ & 465 & 10.5 & 105 & 12.1 & 100 & 16.0 & \\
\hline $5-9$ & 382 & 8.6 & 89 & 10.2 & 104 & 16.6 & \\
\hline \multicolumn{8}{|c|}{ Cumulative dose score (level×duration)§ } \\
\hline None & 2903 & 65.6 & 531 & 61.1 & 334 & 53.4 & $<0.001$ \\
\hline $0-24$ & 330 & 7.5 & 63 & 7.2 & 41 & 6.5 & \\
\hline $25-49$ & 403 & 9.1 & 106 & 12.2 & 68 & 10.9 & \\
\hline $50-74$ & 350 & 7.9 & 63 & 7.2 & 59 & 9.4 & \\
\hline 75-99 & 223 & 5.0 & 54 & 6.2 & 44 & 7.0 & \\
\hline$\geq 100$ & 217 & 4.9 & 52 & 6.0 & 80 & 12.8 & \\
\hline
\end{tabular}

*Including any participants indicating 'yes, some' or 'yes, a lot' of ETS exposure.

tEach participant had an overall score for total exposure from all three ETS sources. Exposure levels of 'no, none at all', 'yes, some' and 'yes, a lot' were scored as 0,1 and 2 , respectively. Therefore, a participant exposed to ETS 'no, none at all' at home, 'yes, a lot' at work and 'yes, some' in other locations would have a total score of 3 ( $0+2+1)$. ¥Participants with ETS exposure durations of $0,>0-19,20-39$ or $\geq 40$ years were scored as $0,1,2$ or 3 for each exposure source. Overall scores were the sum of the individual scores for the three sources of exposure.

$\S$ Cumulative dose score calculated by multiplying exposure level by exposure duration (years) for each ETS source, and then combining the results for the three sources of exposure. Therefore, a participant exposed to ETS 'yes, some' at home for 20 years, 'yes, a lot' at work for 15 years, and 'yes, some' in other locations for 10 years, would have total score of 60 years $(1 \times 20+2 \times 15+1 \times 10)$.

"None" means "no ETS at all". "No" means "not ETS exposure at either home, work or other places" 
Table 3 Relative risk of severe dementia syndrome according to different sources of ETS exposure and cumulative exposure in the five-province study, China

\begin{tabular}{|c|c|c|c|c|c|c|}
\hline \multirow[b]{3}{*}{ ETS exposure } & \multicolumn{6}{|c|}{ Severe dementia syndromes } \\
\hline & \multicolumn{3}{|c|}{ All participants $(n=5921)$} & \multicolumn{3}{|c|}{ Never smokers $(n=3769)$} \\
\hline & $\mathrm{RR}^{*}$ & $95 \% \mathrm{Cl}$ & $\mathrm{p}$ Value & $\mathbf{R R}^{*}$ & $95 \% \mathrm{Cl}$ & $\mathrm{p}$ Value \\
\hline \multicolumn{7}{|l|}{ Exposure source } \\
\hline \multicolumn{7}{|l|}{ At home } \\
\hline None & 1.00 & & & 1.00 & & \\
\hline No & 1.01 & 0.67 to 1.51 & 0.978 & 0.89 & 0.43 to 1.81 & 0.739 \\
\hline Yest & 1.35 & 1.11 to 1.64 & 0.002 & 1.39 & 1.08 to 1.79 & 0.010 \\
\hline \multicolumn{7}{|l|}{ At work } \\
\hline None & 1.00 & & & 1.00 & & \\
\hline No & 1.15 & 0.94 to 1.40 & 0.161 & 1.11 & 0.76 to 1.64 & 0.585 \\
\hline Yest & 1.59 & 1.02 to 2.48 & 0.039 & 1.98 & 1.21 to 3.24 & 0.006 \\
\hline \multicolumn{7}{|l|}{ In other locations } \\
\hline None & 1.00 & & & 1.00 & & \\
\hline No & 1.19 & 1.08 to 1.31 & 0.001 & 1.20 & 0.90 to 1.60 & 0.210 \\
\hline Yest & 1.41 & 1.00 to 1.98 & 0.051 & 1.53 & 0.97 to 2.39 & 0.065 \\
\hline \multicolumn{7}{|c|}{ Above 3 combined $\ddagger$} \\
\hline None & 1.00 & & & 1.00 & & \\
\hline Some $(1-2) \ddagger$ & 1.22 & 1.06 to 1.40 & 0.005 & 1.22 & 0.94 to 1.57 & 0.130 \\
\hline A lot (3-6)‡ & 1.67 & 1.25 to 2.24 & 0.001 & 2.02 & 1.59 to 2.58 & $<0.001$ \\
\hline \multicolumn{7}{|c|}{ Exposure duration (years) } \\
\hline \multicolumn{7}{|c|}{ At home } \\
\hline None & 1.00 & & & 1.00 & & \\
\hline No & 1.00 & 0.67 to 1.49 & 0.999 & 0.88 & 0.44 to 1.78 & 0.724 \\
\hline$>0-19$ & 1.12 & 0.84 to 1.48 & 0.440 & 1.32 & 0.88 to 1.98 & 0.177 \\
\hline $20-39$ & 1.20 & 1.00 to 1.43 & 0.049 & 1.17 & 0.92 to 1.48 & 0.196 \\
\hline$\geq 40$ & 1.65 & 1.21 to 2.27 & 0.002 & 1.70 & 1.28 to 2.27 & $<0.001$ \\
\hline \multicolumn{7}{|l|}{ At work } \\
\hline None & 1.00 & & & 1.00 & & \\
\hline No & 1.15 & 0.95 to 1.40 & 0.153 & 1.12 & 0.76 to 1.64 & 0.581 \\
\hline$>0-19$ & 1.35 & 0.92 to 1.97 & 0.129 & 1.69 & 0.78 to 3.68 & 0.186 \\
\hline 20-39 & 1.42 & 0.84 to 2.40 & 0.189 & 1.86 & 0.97 to 3.54 & 0.060 \\
\hline$\geq 40$ & 2.05 & 1.32 to 3.19 & 0.001 & 2.39 & 1.52 to 3.76 & $<0.001$ \\
\hline \multicolumn{7}{|c|}{ In other locations } \\
\hline None & 1.00 & & & 1.00 & & \\
\hline No & 1.20 & 1.08 to 1.33 & 0.001 & 1.21 & 0.90 to 1.61 & 0.203 \\
\hline$>0-19$ & 1.10 & 0.76 to 1.59 & 0.630 & 1.48 & 1.10 to 1.99 & 0.009 \\
\hline $20-39$ & 1.32 & 0.86 to 2.04 & 0.209 & 1.18 & 0.54 to 2.59 & 0.682 \\
\hline$\geq 40$ & 1.93 & 1.37 to 2.72 & $<0.001$ & 2.21 & 1.53 to 3.18 & $<0.001$ \\
\hline \multicolumn{7}{|c|}{ Above 3 combined score§ } \\
\hline None & 1.00 & & & 1.00 & & \\
\hline 1 & 1.17 & 0.79 to 1.72 & 0.433 & 1.29 & 0.73 to 2.30 & 0.381 \\
\hline 2 & 0.96 & 0.78 to 1.18 & 0.707 & 0.85 & 0.56 to 1.31 & 0.475 \\
\hline $3-4$ & 1.31 & 1.03 to 1.69 & 0.031 & 1.33 & 0.95 to 1.86 & 0.097 \\
\hline $5-9$ & 1.66 & 1.21 to 2.28 & 0.002 & 1.98 & 1.52 to 2.59 & $<0.001$ \\
\hline \multicolumn{7}{|c|}{ Cumulative dose (level×duration)ף } \\
\hline None & 1.00 & & & 1.00 & & \\
\hline$>0-24$ & 0.99 & 0.76 to 1.28 & 0.919 & 0.94 & 0.60 to 1.50 & 0.809 \\
\hline $25-49$ & 1.15 & 0.93 to 1.42 & 0.199 & 1.11 & 0.82 to 1.51 & 0.502 \\
\hline $50-74$ & 1.18 & 0.87 to 1.59 & 0.281 & 1.16 & 0.76 to 1.79 & 0.488 \\
\hline $75-99$ & 1.39 & 1.03 to 1.84 & 0.028 & 1.34 & 0.76 to 2.36 & 0.305 \\
\hline$\geq 100$ & 1.95 & 1.34 to 2.83 & $<0.001$ & 2.55 & 1.67 to 3.90 & $<0.001$ \\
\hline
\end{tabular}

${ }^{*}$ Adjusted for age, sex, smoking status, urban/rural location, educational level, occupation, income, marital status, religion, current drinking, visiting children or relatives, hypertension, stroke and depressive syndrome, and taking account of the five-province geographical area clustering.

tIncluding participants with 'yes, some' or 'yes, a lot' of ETS exposure.

‡Each participant had an overall score for total exposure from all three ETS sources. Exposure levels of 'no, none at all', 'yes, some' and 'yes, a lot' were scored as 0 , 1 and 2 ,

respectively. Therefore, a participant exposed to ETS 'no, none at all' at home, 'yes, a lot' at work and 'yes, some' in other locations, would have a total score of $3(0+2+1)$.

§Participants with ETS exposure durations of $0,>0-19,20-39$ or $\geq 40$ years were scored as $0,1,2$ or 3 for each exposure source. Overall scores were the sum of the individual scores for the three sources of exposure.

ПCumulative dose score calculated by multiplying exposure level by exposure duration (years) for each ETS source, and then combining the results for the three sources of exposure. Therefore, a participant exposed to ETS 'yes, some' at home for 20 years, 'yes, a lot' at work for 15 years, and 'yes, some' in other locations for 10 years, would have total score of 60 years $(1 \times 20+2 \times 15+1 \times 10)$.

"None" means "no ETS at all". "No" means "not ETS exposure at either home, work or other places" 
in former/current smokers. However, the data for moderate syndromes showed no such relationships (data available on request).

\section{DISCUSSION}

In this large population-based study of dementia in China, we observed a significant increase in the risk of severe dementia syndromes among participants exposed to ETS. The impact of ETS was dose-dependent, and significantly affected both never smokers and former/current smokers.

China is the largest producer and consumer of tobacco in the world: $30 \%$ of the world's cigarettes are consumed by China's 350 million smokers. ${ }^{23}$ A 1996 national survey showed that the prevalence rate for ever smokers was $66.9 \%$ for men and $4.2 \%$ for women over the age of 15 years, and that $53.5 \%$ of nonsmokers were regularly exposed to ETS. ${ }^{23}$ In 2002, eversmoking rates in males and females aged 15 and over were $66.0 \%$ and $3.1 \%$, respectively, and the prevalence of ETS in non-smokers was $51.9 \% .^{24}$ Since the World Health Organization Framework Convention on Tobacco Control (FCTC) came into force in January 2006, the Chinese government has actively promoted the introduction of smoke-free environments in hospitals, in schools, on public transportation and in other public places. ${ }^{25}$ However, the implementation of such policies, and their impact, has been far from satisfactory. Recent data show that the prevalence of ETS among never smokers has not reduced significantly, with $52.5 \%$ exposed to ETS daily. ${ }^{26}$ ETS exposure has many detrimental effects on the cardiovascular system, including increased coagulability of blood platelets, endothelial dysfunction, decreased coronary flow velocity reserves and accelerated atheroma genesis. ${ }^{27}$ Moreover, endothelial dysfunction may be related to reduced clearance of $\beta$-amyloid protein, which is considered to be implicated in the pathogenesis of Alzheimer's disease. ${ }^{28}$ Thus it is not surprising that exposure to ETS was found to increase the risk of dementia syndromes in this study.

In the current study, definitions of dementia syndromes were based on symptoms reflecting cognitive impairment consistent with a diagnosis of dementia. ${ }^{12}$ A score of $\geq 3$ on the GMS-AGECAT indicates an 'organic state' which may also include acute confusional states. The large number of studies which have used GMS-AGECAT ${ }^{29}$ indicate that acute confusional states are common in hospital-based practice. However, the probable rate of $0.5-1 \%$ in the community is small enough to be ignored in most studies of dementia; usually such individuals die or recover and are consequently not included in analysis in multiphase epidemiological studies of dementia. In the Chinese community, severe dementia syndromes diagnosed by the GMS-AGECAT predicted the risk of dementia being diagnosed by psychiatrists. In the Anhui cohort which was followed up over 7.5 years, ${ }^{9}$ those with baseline severe dementia syndromes had an increased risk of incident dementia; after adjusting for age, sex, annual income and hypertensive status, the hazards ratio was 2.36 (95\% CI 1.02 to 5.47). In the earlier data analysis of women in the four-province study, we observed that ETS exposure was also significantly associated with severe dementia diagnosed by the GMS-AGECAT. ${ }^{30}$

\section{Strengths and weaknesses of the study}

The main contribution of this study is that it provides information on the dose-response relationship between ETS exposure and severe dementia syndromes. China has had high levels of both active and passive smoking, ${ }^{23} 31$ and also has the highest number of dementia sufferers in the world, ${ }^{2}$ with increasing rates of dementia in the future suggested, ${ }^{16}$ allowing the association between ETS exposure and dementia syndromes to be examined. A second strength is that we included a relatively large number of study participants and the response rate was high. Although the nature of the study and response rate in the third wave survey in Anhui differed from those in the fourprovince study, separate data analysis of results from the fourprovince study and the Anhui study demonstrated similar findings. In addition to increasing study power, inclusion of the Anhui study data in the analysis allowed us to investigate whether the onset of dementia rendered participants more liable to ETS exposure (reverse causality). Of 1694 participants examined in this study, 116 had severe dementia syndromes at baseline, 219 had moderate syndromes and 1359 did not have dementia, and their prevalences of ETS exposure at wave 3 were $30.2 \%, 35.2 \%$ and $31.0 \%$, respectively $(p=0.444)$. The findings showed no association between baseline dementia syndromes at wave 1 and follow-up ETS exposure at wave 3. A third strength is that we adjusted for 14 important variables, minimising the residual effect of confounding. In addition to accounting for the geographical clustering effect in analysis, we directly calculated the RR of dementia syndromes in relation to ETS, avoiding its conversion from the OR. ${ }^{32}$ We did not use a logistic regression model as it is likely to overestimate the association when the outcome prevalence is common $(>10 \%)$.

Our study has several limitations. First, the study was crosssectional and the causal relationship found between ETS exposure and severe dementia syndromes needs to be confirmed by longitudinal follow-up studies. However, it is unlikely that the data on ETS status were affected by differential reporting bias in non-dementia versus dementia cases as ETS was determined before a diagnosis was established. Most Chinese people are unaware of the potential relationship between dementia and ETS exposure. Thus, bias resulting from over-reporting of exposure in patients with dementia syndromes and their carers was unlikely. Furthermore, we have excluded the possibility of reverse causality with ETS exposure resulting from the onset of dementia syndromes in the Anhui cohort data. Second, we did not measure cotinine level to quantify ETS exposure, which is a major limitation. Self-reported ETS may underestimate exposure, ${ }^{33}$ although previous research has indicated that it satisfactorily differentiates between relative levels of exposure. ${ }^{34}$ Our previous studies ${ }^{18}{ }^{19}$ suggest the combination of the questionnaire and cotinine level measurement increases the statistical power. Thus the association between ETS and dementia symptoms as found in this study may be a conservative estimate.

In conclusion, as far as we know, our study is the first to investigate the relationship between ETS exposure and dementia syndromes. A significant association between ETS exposure and severe dementia syndromes was found. The relationship is dose-independent, and ETS significantly affects never smokers and former/current smokers. The similarity of effects of ETS in smokers and never smokers is consistent with findings in a population-based study in the UK, ${ }^{5}$ suggesting that ETS exposure is a strong risk factor for severe dementia syndromes in the general population. The findings from this study, while needing confirmation from prospective longitudinal research, strengthen the case for public health measures to protect people from exposure to ETS. The increased risk of severe dementia in those exposed to ETS is similar to increased risk of coronary heart disease, ${ }^{35}$ suggesting that urgent preventive measures should be taken. At present 93\% of the world's population live in countries not fully covered by smoke-free public health regulations. ${ }^{36}$ More campaigns against ETS exposure and tobacco use in the 
general population will help decrease the risk of severe dementia and reduce the dementia epidemic worldwide.

Acknowledgements The authors thank the participants and all who were involved in the surveys in the Anhui cohort study and the four-province study.

Contributors RC: study concept and design; ZH, YM, XQ and RC: data collection and supervision; $\mathrm{DZ}, \mathrm{KW}, \mathrm{YC}, \mathrm{MH}, \mathrm{ZH}$ and $\mathrm{RC}$ : analysis and interpretation of data; $R C, K W, Y C$ and JRC: drafting of the manuscript; $D Z, X Q, M H, Z H$ and $Y M$ : critical revision of the manuscript for important intellectual content; $\mathrm{RC}, \mathrm{KW}$ and $\mathrm{ZH}$ : obtaining funding; DZ, ZH, RC and YM: administrative, technical and material support. RC has full access to all of the data in the study and takes responsibility for the integrity of the data and the accuracy of the data analysis.

Funding This work was supported by research grants from the Alzheimer's Research Trust and BUPA Foundation, UK. Dr Dongmei Zhang was funded by the University of Wolverhampton Strategic Research Development Fund. The sponsors of the study had no role in study design, data analysis, data interpretation or writing of the report. The opinions expressed in this report are not necessarily those of the funders.

Competing interests None.

Provenance and peer review Not commissioned; externally peer reviewed.

Open Access This is an Open Access article distributed in accordance with the Creative Commons Attribution Non Commercial (CC BY-NC 3.0) license, which permits others to distribute, remix, adapt, build upon this work non-commercially, and license their derivative works on different terms, provided the original work is properly cited and the use is non-commercial. See: http://creativecommons.org/ licenses/by-nc/3.0/

\section{REFERENCES}

1 England E. Survival after diagnosis of dementia in primary care. BMJ 2010;341: C3530.

2 Ferri $\mathrm{CP}$, Prince M, Brayne C, et al. Global prevalence of dementia: a Delphi consensus study. Lancet 2005;366:2112-17.

3 Anstey KJ, von SC, Salim A, et al. Smoking as a risk factor for dementia and cognitive decline: a meta-analysis of prospective studies. Am J Epidemiol 2007:166:367-78.

4 Cataldo JK, Prochaska JJ, Glantz SA. Cigarette smoking is a risk factor for Alzheimer's Disease: an analysis controlling for tobacco industry affiliation. J Alzheimers Dis 2010;19:465-80.

5 Llewellyn DJ, Lang IA, Langa KM, et al. Exposure to secondhand smoke and cognitive impairment in non-smokers: national cross sectional study with cotinine measurement. BMJ 2009;338:b462.

6 Orsitto $G$, Venice $A$, Turi $F$, et al. Fumo di sigaretta, demenza e declino cognitivo in pazienti anziani ospedalizzati. G GERONTOL (Italy) 2010;58:283-9.

7 Barnes DE, Haight TJ, Mehta KM, et al. Secondhand smoke, vascular disease, and dementia incidence: findings from the cardiovascular health cognition study. Am J Epidemiol 2010;171:292-302.

8 Chen R, Ma Y, Wilson K, et al. A multicentre community-based study of dementia cases and subcases in older people in China-the GMS-AGECAT prevalence and socio-economic correlates. Int I Geriatr Psychiatry 2011;27:692-702.

9 Chen R, Hu Z, Wei L, et al. Incident dementia in a defined older chinese population. PLOS ONE 2011;6:e24817.

10 Chen R, Hu Z, Qin X, et al. A community-based study of depression in older people in Hefei, China-the GMS-AGECAT prevalence, case validation and socio-economic correlates. Int I Geriatr Psychiatry 2004;19:407-13.

11 Chen R, Wei L, Hu Z, et al. Depression in older people in rural China. Arch Intern Med 2005;165:2019-25.

12 Copeland JR, Prince M, Wilson KC, et al. The Geriatric Mental State Examination in the 21st century. Int J Geriatr Psychiatry 2002;17:729-32.
13 Chen R, Tunstall-Pedoe H, Morrison C, et al. Trends and social factors in blood pressure control in Scottish MONICA surveys 1986-1995: the rule of halves revisited. J Hum Hypertens 2003;17:751-9.

14 Chen R, Tunstall-Pedoe H. Socioeconomic deprivation and waist circumference in men and women: The Scottish MONICA surveys 1989-1995. Eur J Epidemiol 2005;20:141-7.

15 Chen R, Hu Z, Wei L, et al. Severity of depression and risk for subsequent dementia: cohort studies in China and the UK. Br J Psychiatry 2008;193:373-7.

16 Chen R, Hu Z, Wei L, et al. Is the relationship between syndromes of depression and dementia temporal? The MRC-ALPHA and Hefei-China studies. Psychol Med 2009;39:425-30

17 Kua EH. A community study of mental disorders in elderly Singaporean Chinese using the GMS-AGECAT package. Aust N Z J Psychiatry 1992;26:502-6.

18 Chen $R$, Tavendale R, Tunstall-Pedoe H. Environmental tobacco smoke and prevalent coronary heart disease among never smokers in the Scottish MONICA surveys. Occup Environ Med 2004;61:790-2.

19 Chen R, Tavendale R, Tunstall-Pedoe H. Measurement of passive smoking in adults: self-reported questionnaire or serum cotinine? I Cancer Epidemiol Prev 2002; 7:85-95.

20 Copeland JR, Chen R, Dewey ME, et al. Community-based case-control study of depression in older people. Cases and sub-cases from the MRC-ALPHA Study. Br J Psychiatry 1999;175:340-7.

21 Chen R, Wei L, Seaton A. Neuropsychological symptoms in Chinese male and female painters: an epidemiological study in dockyard workers. Occup Environ Med 1999:56:388-90.

22 Chen R, Dick F, Seaton A. Health effects of solvent exposure among dockyard painters: mortality and neuropsychological symptoms. Occup Environ Med 1999:56:383-7.

23 Yang G, Fan L, Tan J, et al. Smoking in China: findings of the 1996 National Prevalence Survey. JAMA 1999;282:1247-53.

24 Yang GH, Ma JM, Liu N, et al. (Smoking and passive smoking in Chinese, 2002). Zhonghua Liu Xing Bing Xue Za Zhi 2005;26:77-83.

25 Ministry of Health of the People's Repulic of China. Decision on smoke-free health institutions in China from 2011. Beijing. http://www.moh.gov.cn/publicfiles/business/ htmlfiles/mohbgt/s9510/200905/40804.htm (accessed on 4 Apr 2011). 2009

26 Xiao L, Yang Y, Li Q, et al. Population-based survey of secondhand smoke exposure in China. Biomed Environ Sci 2010;23:430-6.

27 Barnoya J, Glantz SA. Cardiovascular effects of secondhand smoke: nearly as large as smoking. Circulation 2005;111:2684-98.

28 Zlokovic BV. Neurovascular mechanisms of Alzheimer's neurodegeneration. Trends Neurosci 2005;28:202-8

29 Copeland JR, McCracken CF, Dewey ME, et al. Undifferentiated dementia, Alzheimer's disease and vascular dementia: age- and gender-related incidence in Liverpool. The MRC-ALPHA Study. Br J Psychiatry 1999;175:433-8.

30 Chen $R$, Zhang $D$, Chen $Y$, et al. Passive smoking and risk of cognitive impairment in women who never smoke. Arch Intern Med 2012;172:271-3.

31 Wang $C P, M a S J, X u X F$, et al. The prevalence of household second-hand smoke exposure and its correlated factors in six counties of China. Tob Control 2009:18:121-6.

32 Zhang J, Yu KF. What's the relative risk? A method of correcting the odds ratio in cohort studies of common outcomes. JAMA 1998;280:1690-1.

33 DeLorenze GN, Kharrazi M, Kaufman $\mathrm{FL}$, et al. Exposure to environmental tobacco smoke in pregnant women: the association between self-report and serum cotinine. Environ Res 2002:90:21-32.

34 Nondahl DM, Cruickshanks KJ, Schubert CR. A questionnaire for assessing environmental tobacco smoke exposure. Environ Res 2005;97:76-82.

35 He J, Vupputuri S, Allen K, et al. Passive smoking and the risk of coronary heart disease-a meta-analysis of epidemiologic studies. N Engl J Med 1999;340:920-6.

36 Oberg M, Jaakkola MS, Woodward A, et al. Worldwide burden of disease from exposure to second-hand smoke: a retrospective analysis of data from 192 countries. Lancet 2011:377139-46. 